peated administration of the drug. Although absorption of the preparation we used is reportedly better ${ }^{9}$ than other preparations studied, erratic absorption of the large number of $5 \mathrm{mg}$ tablets ingested by our patients-who may have had impaired gastrointestinal function because of recent abdominal surgery-seems most likely to explain the observed wide scatter in plasma prednisolone concentrations. We cannot say whether altered metabolism of the drug in these patients was contributory. Since the patients ate and drank normally during the study we could not assess the extent to which food in the gut influenced drug absorption in group 1. In group 3, however, it appeared that whereas at lower doses the main effect of breakfasting before drug ingestion was to delay prednisolone absorption (which has also been noted with uncoated tablets $\left.{ }^{11}\right)$, at higher doses it also greatly reduced the plasma drug concentrations observed over the period studied.

Such very low plasma prednisolone concentrations as observed in some of our patients might be potentially hazardous, possibly favouring graft rejection. Although administration of the drug to patients who are fasting may improve intestinal absorption, this seems unlikely to be a complete answer. Possibly the enteric coating is responsible for erratic absorption. Since any advantage that has been claimed for the coating in preventing peptic ulceration is questionable, ${ }^{11}$ the continued use of this preparation needs reappraisal. Alternatively, it may be that absorption of the drug given as a large number of small tablets is less uniform than if the same dose was administered as one or more larger tablets. Clearly, such implications warrant further study.

We thank Professor R Y Calne and Dr D B Evans for allowing us to study patients under their care. Financial support from Pharmax Limited and the Arthritis and Rheumatism Council is gratefully acknowledged.

\section{References}

1 West, H F, British Medical fournal, 1959, 2, 680.

2 Chakraborty, J, et al, British fournal of Clinical Pharmacology, 1976, 3, 903

${ }^{3}$ Meikle, A W, Weed, J A, and Tyler, F H, fournal of Clinical Endocrinology and Metabolism, 1975, 41, 717 .

4 Sandberg, A A, and Slaunwhite, W R, Fournal of Clinical Endocrinology and Metabolism, 1957, 17, 1040.

5 Sherlock, J E, and Lerreri, J M, Nephron, 1977, 18, 208.

${ }^{6}$ Morrison, P J, Bradbrook, I D, and Rogers, H J, British fournal of Clinical Pharmacology, 1977, 4, 597.

Wilson, C G, May, C S, and Paterson, J W, British fournal of Clinical Pharmacology, 1977, 4, 351

* Hulme, B, James, V H T, and Rault, R, British fournal of Clinical Pharmacology, 1975, 2, 317.

${ }^{9}$ Lee, D A H, et al, British fournal of Clinical Pharmacology. In press.

10 Uribe, M, et al, Gastroenterology, 1976, 71, 362.

\title{
Raised blood pressure and plasma noradrenaline concentrations in teenagers and young adults selected from an open population
}

\author{
A HOFMAN, F BOOMSMA, M A D H SCHALEKAMP, H A VALKENBURG
}

British Medical fournal, 1979, 1, 1536-1538

\section{Summary and conclusions}

Plasma noradrenaline (PNA) concentrations were measured in 38 subjects aged $13-23$, who were followed up for two to four years after an initial blood-pressure (BP) reading of $140 / 90 \mathrm{~mm} \mathrm{Hg}$ or over was obtained, and in 39 age-matched controls from the same open population. Subjects who were hypertensive when the PNA concentration was measured had a significantly higher concentration (351 SE $26 \mathrm{pg} / \mathrm{ml})$ compared with their controls $(248+29 \mathrm{pg} / \mathrm{ml})$. Furthermore, in those subjects in whom the mean arterial pressure decreased by under $5 \%$ during the follow-up period the mean concentration was $363 \pm 27 \mathrm{pg} / \mathrm{ml}$, compared with $271 \pm 29 \mathrm{pg} / \mathrm{ml}$ in their controls. PNA concentrations and systolic BP were positively correlated. A positive association between PNA concentrations and age was observed in the controls but not the subjects with hypertension, owing to the higher concentrations in younger hypertensive subjects.

Medical Faculty, Erasmus University, Rotterdam, The Netherlands A HOFMAN, MD, resident, department of epidemiology

F BOOMSMA, PHD, research chemist, department of internal medicine I $M$ A D H SCHALEKAMP, MD, senior lecturer, department of internal medicine I

H A VALKENBURG, MD, professor of epidemiology
These findings support the hypothesis that excessive sympathetic activity is related to early essential hypertension.

\section{Introduction}

Evidence is increasing that essential hypertension has its roots in childhood. Persistently raised blood pressure (BP) is not uncommon in children, ${ }^{1-3}$ who tend to keep their relative positions in the distribution of BP over time, ${ }^{45}$ possibly from the first months of life. ${ }^{6}$ The hypothesis has been proposed that overactivity of the sympathetic nervous system plays an important part in the pathogenesis of essential hypertension in its early phase, and that other factors-for example, kidney changes-are more important later. ${ }^{7}$ As a reflection of this, plasma catecholamine concentrations would be expected to be increased in young people with raised BP. Until now only studies of plasma catecholamine concentrations in adults ${ }^{8-1 s}$ and a few adolescents ${ }^{14}$ have been reported, and the data have been equivocal. We have measured the plasma noradrenaline (PNA) concentration in young people with potential hypertension and matched controls selected from the same population.

\section{Subjects and methods}

Blood pressure was measured as part of a tracking study of indicators of cardiovascular risk (EPOZ study) in 3924 children and teenagers initially aged $5-19$, representing $82 \%$ of the population in that age group living in two districts in a Dutch town. Subjects with an 
initial BP reading of $140 / 90 \mathrm{~mm} \mathrm{Hg}$ or over were re-examined at least five times during a follow-up period varying from two to four years. They were ranked, using the per cent decrease in mean arterial pressure (MAP; MAP = diastolic pressure + pulse pressure $/ 3$ ) during follow-up as compared with the initial examination. According to this ranking all subjects with the smallest (less than $5 \%$ ) decrease in MAP over time (group 1) and all those with the largest decrease (more than 15\%, group 2) were selected for estimation of PNA concentrations. Group 1 comprised 17 male and four female subjects, and group 2 comprised 12 male and five female subjects. All were aged 13-23, and physical examination and urine analysis showed no evidence of secondary hypertension. These subjects are referred to as "potential hypertensives."

Out of all the potential hypertensives, 18 (15 male) had a BP of $130 / 85 \mathrm{~mm} \mathrm{Hg}$ or over when blood was sampled for estimation of PNA concentrations. These subjects are referred to as being hypertensives. Controls matched for age and sex were selected at random from the remainder of the same population. None of the subjects or controls received medication, and all were on their usual, unrestricted diets.

In a standardised protocol $\mathrm{BP}$ was measured by two trained observers, using a random-zero sphygmomanometer ${ }^{15}$ with the subjects sitting. The Korotkoff sound V was noted as diastolic BP. The subjects were unaware of their BP group. They were asked not to eat, drink, or smoke for at least 90 minutes before the venepuncture, which was performed after 30 minutes' recumbency. Blood sampling was carried out only between $2 \mathrm{pm}$ and $4 \mathrm{pm}$, when circadian variation is smallest, ${ }^{16}$ and cases and controls were studied on the same occasions. Blood was collected in cold heparinised $10 \mathrm{ml}$ tubes containing $15 \mathrm{mg}$ glutathione and centrifuged immediately. The plasma was frozen to $-20^{\circ} \mathrm{C}$. PNA concentrations were measured by a modification of the radioenzymatic method of Henry et al, ${ }^{17}$ in which phenylethanolamine- $N$-methyl transferase and tritiated $S$ adenosyl-L-methionine are used for $N$-methylation of PNA. The between and within coefficients of the measurement are below $10^{\circ}{ }_{0}$

Statistical analysis-Data analysis was performed with a BMD package implemented in a PDP11 computer. For group mean comparisons matched pairs were formed and the $t$ test for unpaired observations with pooled variances was used. The $P$ values correspond to a two-tailed test of significance. Due to missing values not all subjects could be used in group mean comparisons; this explains the differences in numbers in the various analyses.

\section{Results}

The distribution of PNA concentrations in potential hypertensives was more or less normal, with a slight skew to the right. In controls, however, a bimodal distribution was found (fig 1). No significant differences in mean PNA concentrations between the sexes were observed. The subjects who were hypertensive at the time of blood sampling had higher PNA concentrations than their matched controls. There were no significant differences in pulse rate and the number of cigarettes smoked daily (table I). When the two groups of potential hypertensives were pooled they had higher PNA concentrations than the controls (table II). This difference, however, was mainly due to the subjects who showed the smallest decrease in MAP over time (group 1), who differed from the controls in respect of the mean systolic BP and PNA concentration. By contrast, subjects in group 2 differed in respect of only mean diastolic pressure (fig 2).

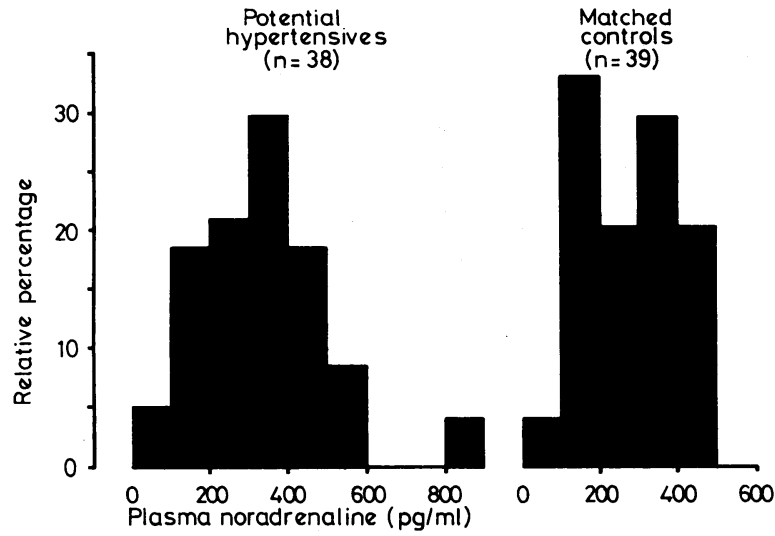

FIG 1 -Distribution of plasma noradrenaline concentrations.
TABLE I-Mean ( $\pm S E$ of mean) plasma noradrenaline (PNA) concentrations, blood pressure, and pulse rate in hypertensive subjects and age-matched controls

\begin{tabular}{|c|c|c|c|c|}
\hline & & $\begin{array}{c}\text { Hypertensive } \\
\text { subjects* } \\
(\mathrm{n}=18)\end{array}$ & $\begin{array}{l}\text { Matched } \\
\text { controls } \\
(n=18)\end{array}$ & $\mathbf{P}+$ \\
\hline $\begin{array}{l}\text { PNA }(\mathrm{pg} / \mathrm{ml}) \\
\text { Blood pressure }(\ddot{\mathrm{mm}} \mathrm{Hg}) \text { : }\end{array}$ & $\ldots$ & $351 \pm 26$ & $248 \pm 29$ & 0.011 \\
\hline $\begin{array}{ccc}\text { Systolic } & \ldots & \cdots \\
\text { Diastolic } & \ddots & \cdots \\
\text { Pulse rate (beats } & \text { min) } & \cdots\end{array}$ & $\because$ & $\begin{aligned} 139 & \pm 2 \\
76 & \pm 2 \\
76 & \pm 3\end{aligned}$ & $\begin{array}{r}125 \pm 2 \\
73 \pm 2 \\
72+3\end{array}$ & $\begin{array}{l}0 \cdot 000 \\
0 \cdot 200 \\
0 \cdot 408\end{array}$ \\
\hline Age (years) $\quad \ldots \quad \ldots$ & $\therefore$ & $18 \cdot 8=0 \cdot 8$ & $18 \cdot 4 \pm 0.6$ & 0.665 \\
\hline
\end{tabular}

* Blood pressure $130 / 85 \mathrm{~mm} \mathrm{Hg}$ or over at time of blood sampling for estimations of PNA concentrations.

†Two-tailed test.

TABLE II-Mean ( $\pm S E$ of mean) plasma noradrenaline (PNA) concentrations and blood pressures in two groups of potential hypertensives aged 13-23 and their age-matched control.

\begin{tabular}{|c|c|c|c|c|}
\hline & & $\begin{array}{c}\text { Potential } \\
\text { hypertensives }\end{array}$ & $\begin{array}{l}\text { Matched } \\
\text { controls }\end{array}$ & $\mathrm{P}_{+}^{+}$ \\
\hline \multirow[b]{2}{*}{ Group $1 *(n=19)$} & \multirow{2}{*}{$\begin{array}{l}\text { PNA }(\mathrm{pg} / \mathrm{ml}) \\
\text { Blood pressure }(\mathrm{mm} \mathrm{Hg}): \\
\text { Systolic } \\
\text { Diastolic }\end{array}$} & $363 \pm 27$ & $271 \pm 29$ & 0.027 \\
\hline & & $\begin{array}{r}134 \pm 3 \\
74 \pm 3\end{array}$ & $\begin{array}{r}123 \pm 2 \\
72 \pm 2\end{array}$ & $\begin{array}{l}0.005 \\
0.563\end{array}$ \\
\hline \multirow[b]{2}{*}{ Group $2+(n=17)$} & \multirow{2}{*}{$\begin{array}{l}\text { PNA }(\mathrm{pg} / \mathrm{ml}) \\
\text { Blood pressure }(\mathrm{mm} \mathrm{Hg}): \\
\text { Systolic } \\
\text { Diastolic }\end{array}$} & $305 \pm 41$ & $293 \pm 28$ & 0.802 \\
\hline & & $\begin{array}{r}126+2 \\
75+2\end{array}$ & $\begin{array}{r}120 \pm 2 \\
67 \pm 2\end{array}$ & $\begin{array}{l}0.076 \\
0.002\end{array}$ \\
\hline \multirow[b]{2}{*}{ Total $(\mathrm{n}=36)$} & \multirow{2}{*}{$\begin{array}{l}\text { PNA }(\mathrm{pg} / \mathrm{ml}) \\
\text { Blood pressure }(\mathrm{mm} \mathrm{Hg}): \\
\quad \text { Systolic } \\
\quad \text { Diastolic }\end{array}$} & $336 \pm 24$ & $281 \pm 20$ & 0.087 \\
\hline & & $\begin{array}{r}130 \pm 2 \\
74 \pm 2\end{array}$ & $\begin{array}{r}122 \pm 2 \\
69 \pm 2\end{array}$ & $\begin{array}{l}0.001 \\
0.025\end{array}$ \\
\hline
\end{tabular}

*Subjects with initial BP of $140 / 90 \mathrm{~mm} \mathrm{Hg}$ or more and smallest (less than $5 \%$ ) decrease in mean arterial pressure during follow-up period.

tSubjects with initial BP of $140 / 90 \mathrm{~mm} \mathrm{Hg}$ or more and largest (more than $15 \%$ ) decrease in mean arterial pressure during follow-up period. Two-tailed test.

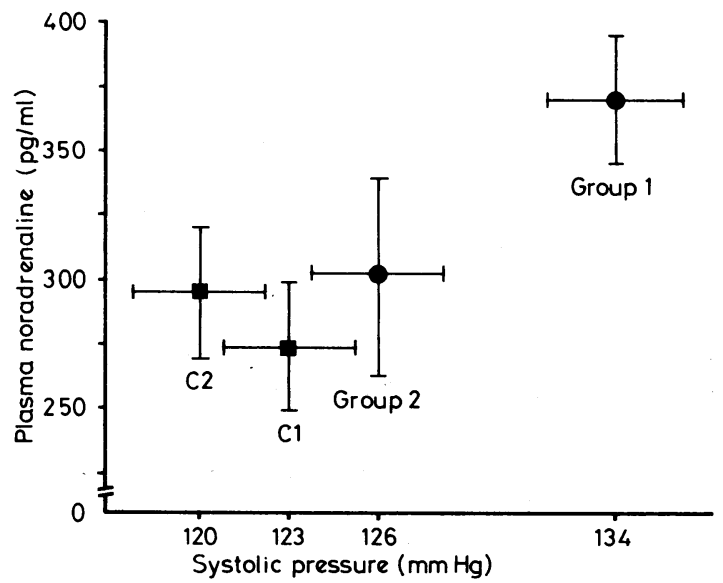

FIG 2-Relations between mean plasma noradrenaline concentrations and systolic blood pressure in subjects with smallest decrease in mean arterial pressure (MAP) over time (group $1 v$ controls $(\mathrm{C} 1): \mathrm{P}=0.03$ ) and subjects with largest decrease in MAP (group $2 v$ controls $(\mathrm{C} 2): \mathbf{P}=0 \cdot 8$ ).

Figure 3 shows the PNA concentrations plotted against age. In the two groups of potential hypertensives no significant relation between these variables was found $(r=-0.14, P=0.41)$, but in the controls the PNA concentration was positively associated with age $(\mathbf{r}=0.30, P=0.05)$. No significant relation between the PNA concentration and BP emerged when subjects and controls were considered separately. When they were considered together a positive correlation could be shown between PNA concentrations and systolic BP $(r=0.21, P=0.06)$ but not between PNA concentrations and diastolic pressure $(r=0 \cdot 11, P=0.34)$.

Correlation coefficients of PNA concentrations with pulse rate, pulse pressure, body-mass index, and number of cigarettes smoked daily did not reach significance. 


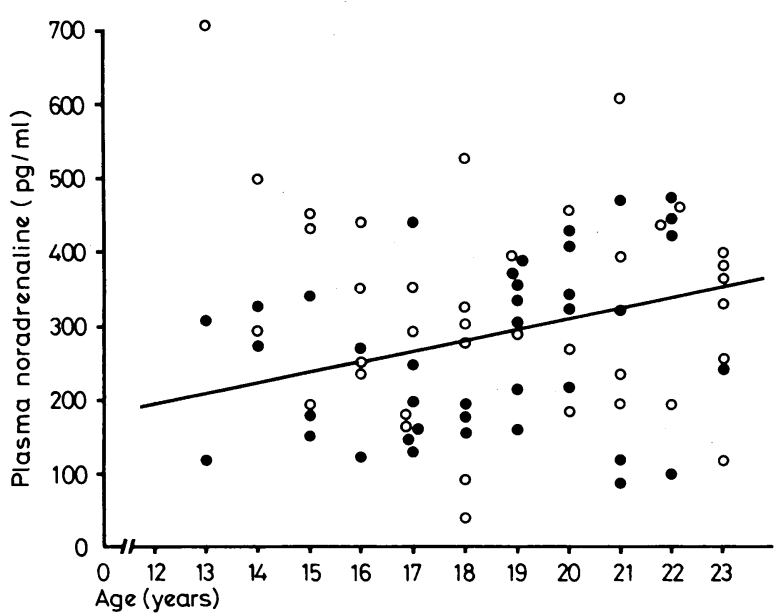

FIG 3-Relation between plasma noradrenaline concentrations and age. $O=$ Potentially hypertensive subjects $(\mathrm{n}=38 ; \mathrm{r}=0.14$, $\mathbf{P}=0.41) . \bullet=$ Matched controls $(\mathrm{n}=39 ; \mathrm{r}=0.3, \mathrm{P}=0.05)$.

Regression line of controls given by $y=13 \cdot 1 x-40 \cdot 9$.

\section{Discussion}

In case-control studies recruiting suitable controls is crucial. The present study has an important advantage over others reported: both cases and matched controls were selected from the same open population in an epidemiological investigation, which enlarges comparability. Moreover, the relevant parameters were measured in a rigorously standardised protocol, known to reduce variability..$^{15} 1618$ Studies in adults ${ }^{1012} 13$ have emphasised the need for careful age-matching. The present study shows a positive association between PNA concentrations and age in normotensive controls, even in the rather narrow age range of 13-23 years. This relation was not found in the potential hypertensives, suggesting altered sympathetic outflow in the early stages of essential hypertension.

Subjects who were hypertensive (according to an arbitrary cut-off) had clearly higher PNA concentrations than their matched controls. The subjects with the smallest decrease in MAP over time showed higher systolic BPs and concentrations of PNA than controls. The subjects with the largest decrease in MAP over time had a higher diastolic pressure than controls, but the PNA concentration was the same. These findings suggest that in teenagers and young adults a persistently raised $\mathrm{BP}$ is associated with increased PNA concentrations. Furthermore, systolic rather than diastolic pressure seems to be related to excessive sympathetic activity. This is also supported by the significant, albeit weak, association of systolic but not diastolic pressure with PNA concentrations. The different relations of PNA concentrations with systolic and diastolic pressures might explain the reported similarity of PNA concentrations in normotensive and hypertensive people, ${ }^{10}$ because in that study subjects were primarily selected on the basis of high diastolic BP.

No differences in mean pulse rate between potential hypertensives and their controls were found. This was unexpected, since a positive association between pulse rate and BP in the young has been reported. ${ }^{1}$ Nevertheless, the increased concentrations of PNA in subjects with raised BP shown in this study support the hypothesis that the sympathetic nervous system is important in the pathogenesis of essential hypertension.

We thank the many young people for participating so willingly in the EPOZ study; and Miss E M W Huysen, Miss A M Op den Kelder, Mrs M Lammers, Mrs S I Werdmüller, and Mr A van Laar for technical and computational help. The study is supported by grants from the Netherlands Prevention fund and the Netherlands Health Organisation TNO.

Requests for reprints should be addressed to: Dr A Hofman, Department of Epidemiology, Medical Faculty, Erasmus University, PO Box 1738, Rotterdam, The Netherlands.

\section{References}

1 Miller, R A, and Shekelle, R B, Circulation, 1976, 54, 993.

2 Loggie, J M H, in fuvenile Hypertension, ed M I New and L S Levine. New York, Raven Press, 1977.

3 Rames, L K, et al, Pediatrics, 1978, 61, 245.

${ }^{4}$ Zinner, S H, et al, American fournal of Epidemiology, 1974, 100, 437.

5 Rosner, B, et al, American fournal of Epidemiology, 1977, 106, 306.

${ }^{6}$ De Swiet, M, Fayers, P, and Shinebourne, E A, British Medical fournal, 1976, 2, 9.

7 Brown, J J, et al, Lancet, 1976, 1, 1217.

${ }^{8}$ Louis, W J, Doyle, A E, and Avanekar, S, New England fournal of Medicine, 1973, 288, 599.

9 De Champlain, J, et al, Circulation Research, 1976, 38, 109.

11 Lake, C R, et al, New England fournal of Medicine, 1977, 296, 208.

${ }^{11}$ Esler, M, et al, New England fournal of Medicine, 1977, 296, 405.

12 Sever, P S, et al, Lancet, 1977, 1, 1078

13 Franco-Morselli, R, et al, British Medical fournal, 1977, 2, 1251.

${ }^{14}$ Miura, Y, et al, fapanese Circulation fournal, 1978, 42, 609.

15 Wright, B M, and Dore, C F, Lancet, 1970, 1, 337.

${ }^{16}$ Sauerbier, I, and Von Mayersbach, H, Hormone and Metabolic Research, 1977, 9, 529.

17 Henry, D P, et al, Life Sciences, 1975, 16, 375.

${ }_{18}$ Carruthers, M, et al, Lancet, 1970, 2, 62.

(Accepted 25 April 1979)
ONE HUNDRED YEARS AGO On Monday evening, $\mathrm{Mr}$ Ernest Hart [Editor, $B M F$ ] delivered, at the Memorial Hall, London Street, Bethnal Green, a lecture on the subject of "Coffee-Taverns for the People." Mr J Holms, MP, presided. The lecturer commenced with an allusion to the present commercial distress, which, however, he was happy to think, was not serious in that district: as a matter of fact, work could there be obtained by those who wished to take it. Turning to the immediate topic of the evening, he stated that in the five years ending 1862, four hundred and fifty millions sterling was spent in intoxicating drinks, being at the rate of ninety millions per annum. In the five years just ended, seven hundred and thirteen millions had been spent, or an average of one hundred and forty-two millions a year. The population had increased sixteen per cent during the last fifteen years, whilst the increase of expenditure in drink had been four times that amount. This state of things compared unfavourably with the Continental countries. An earlier introduction of coffee-taverns would, he believed, have produced a more favourable state of things. A glance at our criminal and lunatic statistics followed; and, in conclusion, the lecturer described the progress made by the arduous labours of the directors of the London Coffee-Tavern Company, and the increasing number of coffee-taverns in London and elsewhere, and augured hopefully both for their future success and for the beneficial effects on the drinking habits of the people.The Chairman was much pleased to hear from Mr Hart so many particulars of the coffee-tavern movement. Even from the philanthropic point of view, its success was most desirable; but he trusted also that it would be made to pay, as commercial success was the best guarantee for its permanence and extension; 142 millions sterling was an enormous amount of drinking expenditure, and everything that could be done to reduce that total would be most beneficial. He thought that coffee-taverns as one curative agency ought to be encouraged, and that they should be made so many working-men's clubs. This country was called "merrie England", but the name was wholly misapplied; for a more doleful and dismal country did not exist, in so far as the working classes were concerned; whilst their contemporaries in the Continental countries had abundant facilities for innocent enjoyment. He deplored the existing distress, out of which he could not clearly see his way, and attributed it to foreign competition and to the great ignorance of the people of this country. In the United States, only $4 !$ per cent of the native-born Americans could not read nor write, whereas it was shown that in Lancashire 50 per cent of the women could do neither one nor the other.-The proceedings terminated with votes of thanks to the chairman and the lecturer. (British Medical fournal, 1879.) 